\title{
Community
}

\section{News from the European Optical Society EOS}

DOI 10.1515/aot-2017-0009

\section{EOS Conferences at the World of Photonics Congress}

\section{CDS OPTICAL}

Location: Munich, Germany

Duration: June 26, 2017-June 29, 2017

EOS Optical Technologies include:

- 5th Conference on Manufacturing of Optical Systems

- 4 th Conference on Optofluidics

- 2nd Conference on Light Engineering

- 2nd Conference on Optomechanical Engineering

The four already established conferences will be held for the first time under one title: EOS Optical Technologies. Advancements in technology and innovative manufacturing processes are crucial for optical sector growth in today's global markets. Markets with high developmental momentum include the energy and semiconductor, life sciences, health care and the agri-food industries. Optical technologies play a crucial role in these markets, the importance of sophisticated but economically priced optical components being vital to new products and applications. The EOS conferences tackle all aspects of optical technologies, such as the development and manufacturing of optical systems and components, optofluidics, optomechanical engineering and light engineering.

The optofluidics conference will include a plenary talk by Demetri Psaltis, École Polytechnique Fédérale de Lausanne (EPFL). As one of the founders of the term and the field of optofluidics, and an inventor of countless patents in the field, we look forward to his talk in Munich.

EOS Conferences are held under the umbrella of the World of Photonics Congress 2017, the leading international congress for optical technologies in Europe (June 25-29, 2017).

www.degruyter.com/aot

(c) 2017 THOSS Media and De Gruyter

\section{Early bird registration until 1st June}

Register now at www.conftool.com/wpc2017 and take advantage of the Early Bird Fee (until June 1, 2017). Take part in the leading congress on Optical Technologies: World of Photonics Congress in Munich, June 25-29, 2017.

By registering with EOS you get admission to all conferences held at the World of Photonics, as well as entrance free of charge to the leading international LASER World of PHOTONICS fair. More about the congress: http://www. myeos.org/events/WPC2017

See you in Munich, June 26-29, 2017!

\section{And by the way: Join EOS!}

Join the EOS as an individual member and become a part of the European optics and photonics community! You will start receiving all benefits the moment you sign up.

- Save money on conference registration fees (not only EOS events but also events organized by EOS partner societies and selected EOS co-sponsored events!)

- Join and attend ALL the conferences at the World of Photonics Congress, June 25-29 (organized by EOS and other societies) with a reduced ticket price as an EOS member. This ticket also includes FREE access to the leading trade fair LASER World of Photonics. To get the discount, join as a member and register with EOS Optical Technologies: www.conftool.com/ wpc2017

- Free subscriptions to journals

- Full voting rights

- Regular electronic EOS member newsletter

- Postal communication from EOS, such as event announcements

For a detailed overview of the membership benefits, please see www.myeos.org/members/individual or contact the EOS Office at info@myeos.org.

Individual Membership for 2017 only €50, students $€ 10$ ! You may find all the details at http://www.myeos. org/members/howtojoin 


\section{1 societal members in Europe}

Currently, 21 national optical societies in Europe are societal members of the EOS. Societies can join the EOS as a branch or as an affiliated society. The following national optical societies in Europe are members of the EOS:

\section{EOS branches (light blue countries):}

DGaO (Germany), Photonics Finland (Finland), SFO (France), IOP Optical Group (UK and Ireland),
SSOM (Switzerland), SOS (Sweden), SIOF (Italy), HOS (Hungary), LOS (Latvia), and PhotonicsNL (The Netherlands).

\section{EOS affiliated societies (dark blue countries):}

NPS-OD (Norway), DOPS (Denmark), Promoptica (Belgium), SEDOPTICA (Spain), SPOF (Portugal), PPS-OD (Poland), DOQE-RPS (Romania) and CSSF (Czech and Slovak Republic), WLT (Germany), LAS (Russia), and USPAO (Ukraine).

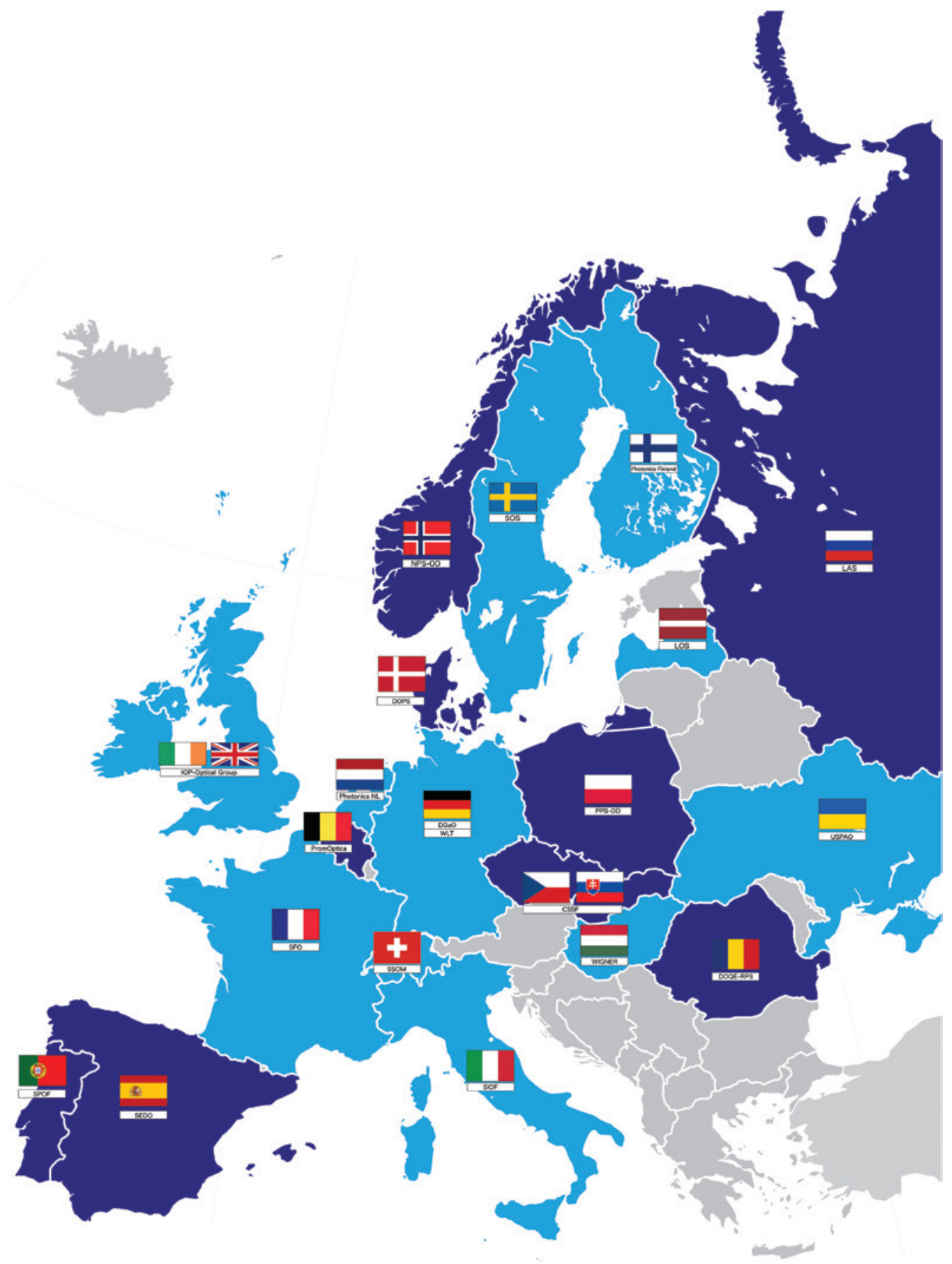

